\title{
Buforin III Analogs Bind to DNA and Actin and Inhibit Bacterial Growth
}

\author{
Nurit Beyth ${ }^{1}$, Edna Blotnick-Rubin ${ }^{2,}$, , Yael Houri-Haddad ${ }^{1}$, Shaul Beyth $^{3}$, Andras Muhlrad ${ }^{4}$ \\ ${ }^{1}$ Department of Prosthodontics, Hebrew University-Hadassah School of Dental Medicine, Jerusalem, Israel \\ ${ }^{2}$ Department of Medical Neurobiology, Institute for Medical Research-Israel-Canada, Hebrew University of Jerusalem, Jerusalem, Israel \\ ${ }^{3}$ Orthopedic Surgery Complex, Hadassah University Hospital, Jerusalem, Israel \\ ${ }^{4}$ Institute of Dental Sciences, Hebrew University-Hadassah School of Dental Medicine, Jerusalem, Israel
}

Email address:

ednab@ekmd.huji.ac.il (E. Blotnick-Rubin)

${ }^{*}$ Corresponding author

\section{To cite this article:}

Nurit Beyth, Edna Blotnick-Rubin, Yael Houri-Haddad1, Shaul Beyth, Andras Muhlrad. Buforin III Analogs Bind to DNA and Actin and Inhibit Bacterial Growth. Advances in Biochemistry. Vol. 6, No. 5, 2018, pp. 39-46. doi: 10.11648/j.ab.20180605.11

Received: October 25, 2018; Accepted: November 9, 2018; Published: December DD, 2018

\begin{abstract}
Buforin is a cationic antimicrobial peptide (AMP) from the stomach of toads. Buforin II is a derivative of this naturally occurring peptide. Buforin IIB is a synthetic analog of buforin II containing a model $\alpha$-helical sequence (3xRLLR) at the $\mathrm{C}$-terminus. To further increase the antimicrobial activity and decrease toxicity to eukaryotic cells, new derivatives (buforin III analogs) were designed by substituting amino acids in the buforin IIB sequence. In this work, the antimicrobial activity and the actin- and DNA-binding characteristics of buforin IIIB (RVVRQWPIGRVVRRVVRRVVR) and the newly synthetized buforin IIIE (RLLLRQWPIGRLLRRLLRRLLR) were studied. The antimicrobial activity of buforin IIIB (measured against $E$. coli and E. faecalis) was significantly greater than that of buforin IIIE, while both peptides were nontoxic to macrophages at the minimal concentrations required to inhibit microbial growth. Actin, which inhibited the antimicrobial activity of the two buforin III analogs, was bundled by both peptides; however, less buforin IIIE than buforin IIIB was needed for bundling. Higher levels of $\mathrm{NaCl}$ were needed to unbundle actin bundled by buforin IIIE than actin bundled by buforin IIIB, which indicates that buforin IIIE binds more strongly to actin than buforin IIIB. Actin bundled by either peptide was dissociated with the same concentration of DNA; however, buforin IIIE bound more strongly to DNA than buforin IIIB. These results contribute to the understanding of the antimicrobial mechanism of cationic AMPs in general and histone-derived peptides in particular.
\end{abstract}

Keywords: Histone H2A-derived Antimicrobial Peptides, Buforin IIIB, Buforin IIIE, Antimicrobial Activity, Bundling F-actin, Binding to DNA

\section{Introduction}

Antimicrobial peptides (AMPs) are short (10-50 amino acid residues) peptides [1]. AMPs have an overall positive charge and also contain hydrophobic residues [1]. Buforin is an antimicrobial peptide found in the stomach of the toad Bufo bufo gargarizans [2]. Buforin can be produced from histone $\mathrm{H} 2 \mathrm{~A}$ by proteolysis with pepsin $\mathrm{C}$ [3]. Buforin has a 35 amino acid sequence that is identical to the N-terminal DNA binding sequence of histone H2A [4]. Histones are small cationic proteins that act as spools for DNA to wind around and are the major constituents of chromatin in eukaryotic cell nuclei. Histones are also found free in the cell, unbound to DNA. Histones, including histone H2A and its buforin derivatives, possess antimicrobial activity [5-7] that is based on interactions with the microbial membrane. Histones also react with other negatively charged particles, including actin filaments, which can be bundled by histones [8]. Buforin II is a smaller derivative of buforin and is produced from buforin by treatment with the endoproteinase Lys-C. Its antimicrobial activity is significantly higher than that of the parent molecule [9]. Buforin II, whose 21 amino acid sequence is identical to the $\mathrm{N}$-terminal sequence of histone $\mathrm{H} 2 \mathrm{~A}$, kills bacteria mainly by translocating into the 
microbial cell without disrupting the cell membrane [10]. The killing mechanism of buforin II is thought to be based on its interaction with DNA [11] inside microbial cells. For AMPs to be used as therapeutic agents in infectious diseases, it is essential that they have high antimicrobial activity without toxicity to the cells of the host organism. A synthetic derivative of buforin II, buforin IIB, has a proline hinge (QFPVG) between the N-terminal $\alpha$-helix and the $\alpha$-helical sequence (3xRLLR) at the C-terminus [9]. This derivative has higher antimicrobial activity than the original buforin II [9]. The proline residue and its location in the buforin IIB sequence critically influence the antimicrobial activity of the molecule [12]. Buforin IIB has a low toxicity, but at high concentrations, buforin IIB still kills eukaryotic cells. To further decrease toxicity and increase antimicrobial activity, new derivatives of buforin II, buforin III analogs, were designed by Jang et al. [13]. The proline hinge region of buforin IIB, QFPVG, was changed in the buforin III analogs by substituting two hydrophobic residues, phenylalanine and valine, with tryptophan and isoleucine (QWPIG). This substitution eliminated the toxicity of the buforin IIIA analog at the minimal concentration needed for inhibition of microbial growth without affecting the antimicrobial activity. Next, the four N-terminal amino acids of buforin IIIA (RAGL) were substituted with an $\alpha$-helical sequence (RVVR or KLLK), which resulted in a two-fold increase in antimicrobial activity (buforin IIIB and buforin IIIC, respectively), in addition to eliminating the toxicity [13].

In this study, the role of hydrophobic residues in the $\alpha$ helices of buforin III peptides was investigated. We designed a new buforin III analog, buforin IIIE (RLLR QWPIG RLLR RLLR RLLR), by substituting the valine residues in buforin IIIB (RVVR QWPIG RVVR RVVR RVVR) with leucines. The antimicrobial activity and the effect of actin filaments (F-actin) on the activity of buforin IIIE and buforin IIIB were compared. We also studied the binding of these analogs to DNA and F-actin and the competition between DNA and actin for binding to these peptides. Our aim was to further characterize the molecular properties and mechanisms of action of the two buforin III analogs in order to facilitate their use in therapeutic applications.

\section{Materials and Methods}

\subsection{Materials}

ATP, ADP, dithiothreitol (DTT), thiazole orange, and deoxyribonucleic acid (DNA) from calf thymus were purchased from Sigma Chemical Co. (St Louis, MO). Acetone dry powder prepared from rabbit skeletal muscle was purchased from Pel-freeze Biologicals (Rogers, AR). Synthetic buforin IIIB and buforin IIIE of $98 \%$ purity were purchased from Genemed Synthesis Inc. (San Antonio, TX). Cell Proliferation Kits containing 2,3-bis(2-methoxy-4-nitro5-sulfophenyl)-5-[(phenylamino)carbonyl]-2H-tetrazolium hydroxide (XTT) and N-methyl dibenzopyrazine methyl sulfate (PMS) reagents were purchased from Biological
Industries Ltd. (Beit Haemek, Israel).

\subsection{Preparation of Bacterial Suspension and Growth Inhibition Assay}

The microorganisms used in this study were obtained from the American Type Culture Collection (ATCC) and included Escherichia coli (ATCC 25922) and Enterococcus faecalis (ATCC V583). The antimicrobial activity of each peptide was determined using the broth microdilution assay [14]. Briefly, bacteria were cultured overnight in $5 \mathrm{ml}$ of brainheart infusion (BHI) broth (Difco, Detroit, MI, USA) at $37^{\circ} \mathrm{C}$ under aerobic conditions. Aliquots of each culture were transferred to $50 \mathrm{~mL}$ of fresh medium, incubated for an additional $4 \mathrm{~h}$, and resuspended in fresh BHI broth. The relationship between the absorbance at $650 \mathrm{~nm}$ and colony forming units (CFU) was determined for each microorganism by spreading serial dilutions of the cell suspensions onto TSB agar plates. The cell suspensions were diluted to $2 \times 10^{5}$ CFU/ml. Each well in a 96-well plate (Nunc 96 microtiter plates, Roskilde, Denmark) was filled with $180 \mu \mathrm{L}$ of the diluted cell suspension and $20 \mu \mathrm{L}$ of serially diluted peptide samples. The inhibition of growth was determined by measuring the absorbance at $650 \mathrm{~nm}$ with a Model 550 Microplate Reader (Bio-Rad, Hercules, CA). The optical density of each well was recorded every 20 min using a microplate reader (VERSAmax tunable microplate reader, Molecular Devices, Sunnyvale, CA, USA) at $37^{\circ} \mathrm{C}$ for $24 \mathrm{~h}$. The lowest concentration of peptide that completely inhibited growth was defined as the 'minimal inhibitory concentration' (MIC). The MICs were calculated from the average values obtained in triplicate in three independent experiments.

\subsection{Toxicity Assay}

This assay is based on an XTT cell proliferation method [15] and was carried out according to the protocol and Biological Industries kit (Beit Haemek Ltd., Israel). Briefly RAW 264 rat macrophage cells were cultivated in a flat 96well plate containing $200 \mu \mathrm{l}$ of growth media at $37{ }^{\circ} \mathrm{C}$ under anaerobic conditions. After $24 \mathrm{~h}$ incubation, $180 \mu \mathrm{l}$ of new media plus $20 \mu \mathrm{l}$ of buforin solution were added, and the incubation was continued for an additional $24 \mathrm{~h}$. At the end of the incubation, $100 \mu \mathrm{l}$ of cell-containing medium was removed, and $50 \mu \mathrm{l}$ of XTT reagent solution containing $1 \mu \mathrm{l}$ of PMS activator solution was added, followed by incubation in the dark for $3 \mathrm{~h}$. Cell proliferation was determined by the increase in absorbance at $450 \mathrm{~nm}$ measured with a Model 550 Microplate Reader (Bio-Rad, Hercules, CA).

\subsection{Preparation of Actin}

CaATP-G-actin was prepared as described by Spudich and Watt [16] from acetone-dried powder of the back and leg muscles of rabbits after myosin extraction. This preparation contains highly homogeneous actin in purities greater than $90 \%$. CaATP-G-actin was stored in a buffer containing $5 \mathrm{mM}$ TrisHCl, $0.2 \mathrm{mM} \mathrm{CaCl}, 0.2 \mathrm{mM} \mathrm{ATP}$, and $0.5 \mathrm{mM} \beta$ mercaptoethanol, at $\mathrm{pH} 8.0$ (CaATP-G-buffer). MgF-actin 
was polymerized from CaATP-G-actin through $30 \mathrm{~min}$ incubation with $2 \mathrm{mM} \mathrm{MgCl}_{2}$ at room temperature. $\mathrm{MgF}$ actin was diluted for further treatments in $\mathrm{MgF}$-buffer containing $5 \mathrm{mM}$ MOPS, $2 \mathrm{mM} \mathrm{MgCl} 2,0.2 \mathrm{mM}$ ATP, and 0.5 $\mathrm{mM}$ DTT at $\mathrm{pH}$ 7.4. The concentrations of rabbit skeletal muscle CaATP-G-actin and $\mathrm{Mg}$-F-actin were determined spectrophotometrically using the extinction coefficients $\mathrm{E} 1 \% 290=11.5 \mathrm{~cm}^{-1}$ (the optical density of actin was measured in the presence of $0.5 \mathrm{M} \mathrm{NaOH}$, which shifts the absorbance maximum from 280 to $290 \mathrm{~nm}$ ). The molecular mass of skeletal actin was assumed to be $42 \mathrm{kDa}$.

\subsection{Thiazole Orange DNA Binding Assay}

DNA binding was measured using a fluorescence intercalator displacement (FID) assay [11, 17]. Briefly, a quartz cuvette was loaded with thiazole orange $(0.55 \mu \mathrm{M})$ in STE buffer (10 mM TrisHCl, $50 \mathrm{mM} \mathrm{NaCl}, 1 \mathrm{mM}$ EDTA, $\mathrm{pH}$ 8.0). The fluorescence of this solution was measured (excitation $509 \mathrm{~nm}$, emission $527 \mathrm{~nm}$ ) and normalized to $0 \%$ relative fluorescence. DNA in STE buffer was added to the cuvette $(5 \mu \mathrm{g} / \mathrm{ml}$ final concentrations). After equilibrating for $5 \mathrm{~min}$, the fluorescence of this solution was measured and normalized to $100 \%$ relative fluorescence. Aliquots of a peptide solution were then added with mixing, with 5 min of incubation after each addition before the fluorescence measurements. The $\mathrm{C}_{50}$ (concentration of peptide required to reduce the fluorescence to $50 \%$ of the initial emission) was determined by a curve fit to the data.

\subsection{Monitoring F-actin Bundling by Sedimentation}

The extent of actin bundling by buforins was measured by centrifugation at $20,800 \times \mathrm{g}$ for $8 \mathrm{~min}$ in an Eppendorf

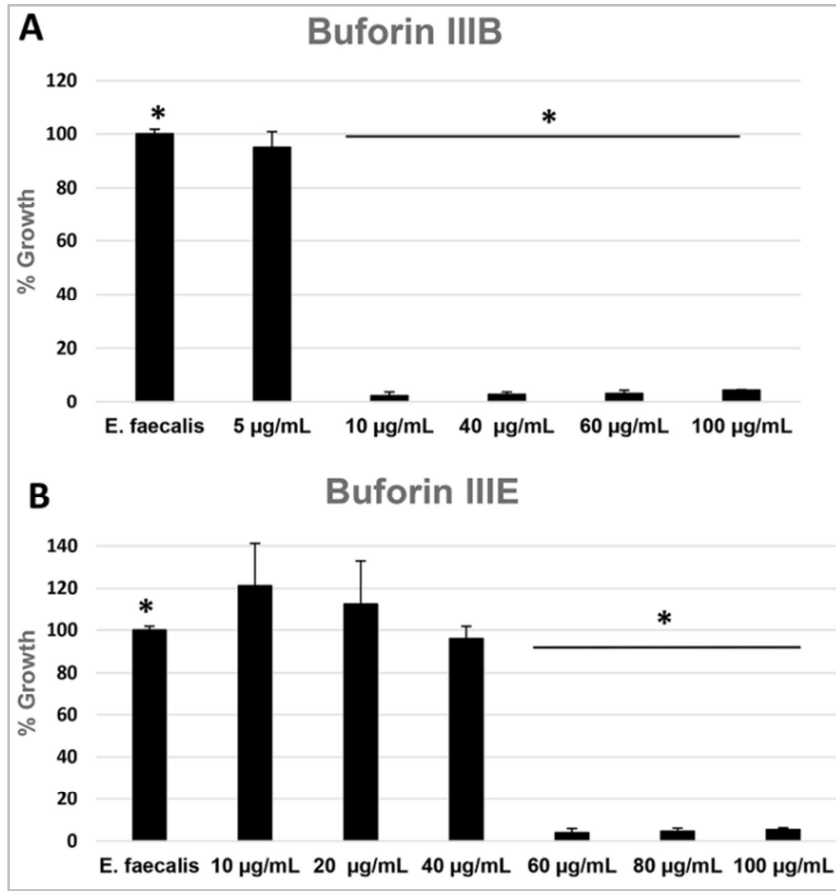

centrifuge rotor. The centrifugations were carried out at $4{ }^{\circ} \mathrm{C}$. The supernatants were separated by $12 \%$ SDS-PAGE and analyzed by densitometry using the TINA $2.07 \mathrm{~d}$ software.

\subsection{Statistical Analysis}

Student's t test and one-way ANOVA were used for calculations of $\mathrm{p}$ values to evaluate the significance. $*=$ $\mathrm{p}<0.05, * *=\mathrm{p}<0.01, * * *=\mathrm{p}<0.005$. Unless specified, all presented data are the means of three independent experiments performed in triplicate. All presented SDS gels blots are representative of three independent experiments.

\section{Results}

\subsection{Antimicrobial Activity of Buforin III Analogs and Inhibition of Antibacterial Activity by Actin}

The antibacterial activities of buforin IIIB and buforin IIIE were measured against E. coli and E. faecalis (Figure 1). Both analogs inhibited the growth of the two bacteria, however, lower concentrations of buforins were needed for the inhibition of $E$. coli growth compared to those needed to inhibit E. faecalis. Additionally, the minimal inhibitory concentration (MIC) of buforin IIIB was significantly lower than that of buforin IIIE (Table 1).

Table 1. Minimal inhibitory concentrations (MIC) of buforin IIIB and buforin IIIE $(\mu \mathrm{g} / \mathrm{ml})$.

\begin{tabular}{lll}
\hline & Buforin IIIB & Buforin IIIE \\
\hline E. coli & $5 \pm 2$ & $20 \pm 3$ \\
E. faecalis & $1 \pm 0.5$ & $40 \pm 5$ \\
\hline
\end{tabular}

C

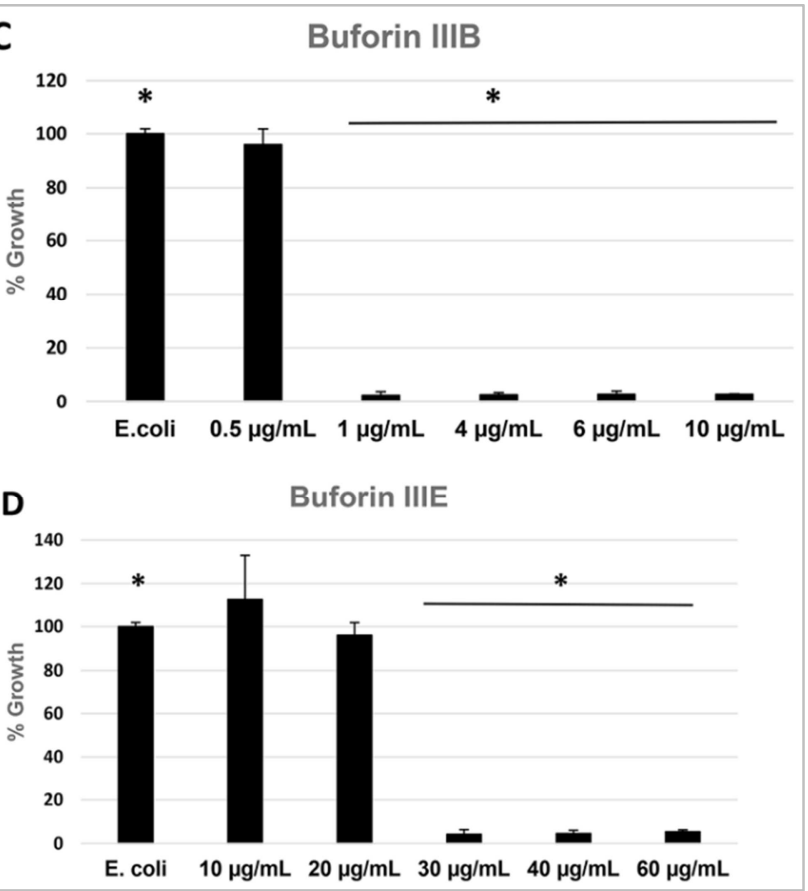

Figure 1. The inhibitory effect of buforin IIIE and buforin IIIB on the growth of E. faecalis and E. coli. Buforins were added to bacterial suspensions, and the bacterial growth was measured as described for the growth inhibition assay (Materials and Methods). Effect of buforin IIIB (A) and buforin IIIE (B) on E. faecalis growth and effect of buforin IIIB (C) and buforin IIIE (D) on E. coli growth. 
The toxicity of these buforin III analogs against macrophages was found to be negligible (Figure 2). At the highest buforin concentration used in the cell viability assay (10 $\mu \mathrm{g} / \mathrm{ml}$ buforin IIIB and $60 \mu \mathrm{g} / \mathrm{ml}$ buforin IIIE), the difference between the values obtained in the absence and presence of buforins was not significant. The bacterial growth was strongly inhibited (Figure 1) by these buforin concentrations.

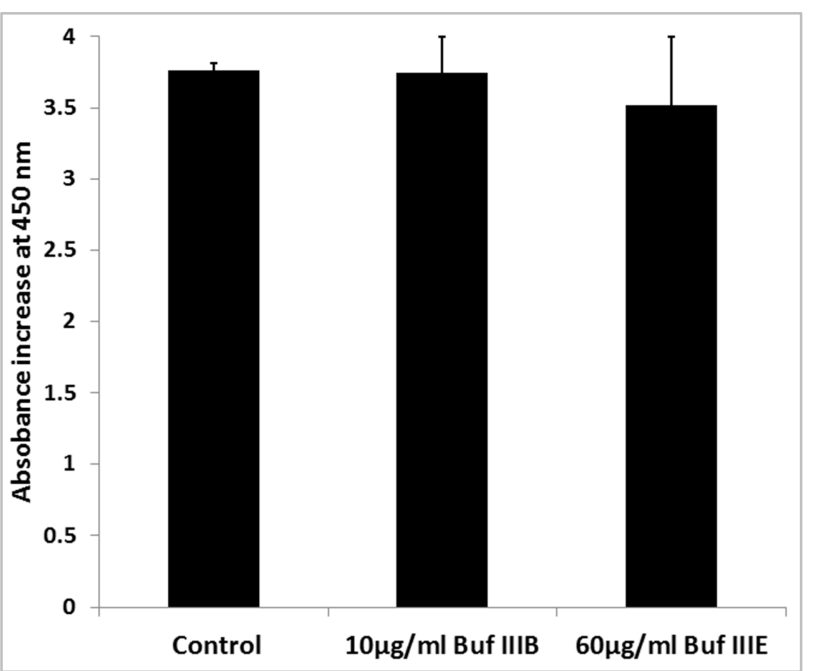

Figure 2. The effect of buforin IIIB and buforin IIIE on the viability of RAW 264 rat macrophage cells was determined as described in the Materials and Methods (Toxicity assay).

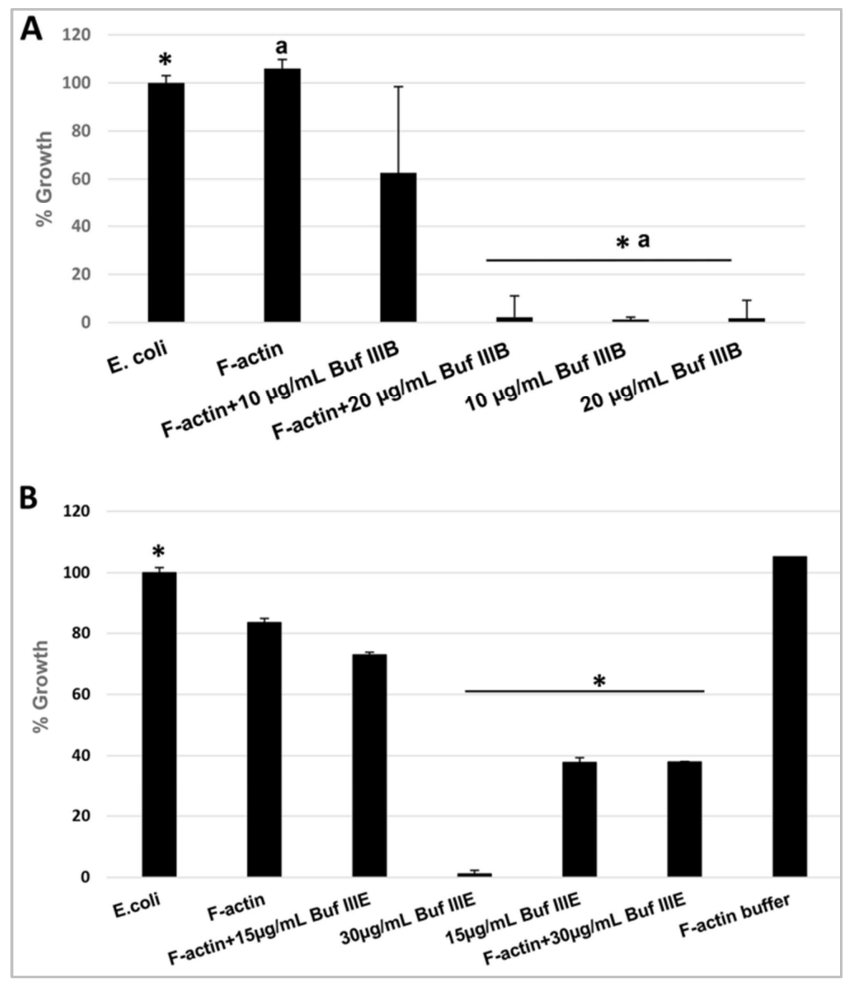

Figure 3. E. coli growth inhibition by buforin IIIB and buforin IIIE is decreased by F-actin. Buforins with and without $10 \mu M(420 \mu \mathrm{g} / \mathrm{ml}) \mathrm{F}$-actin were added to suspensions of E. coli, and the bacterial growth was measured as described in the Materials and Methods (Growth inhibition assay). (A) Buforin IIIB and (B) buforin IIIE.
Negatively charged actin filaments have been shown to inhibit the antimicrobial activity of histone H2A [7], which is the parent molecule of buforins [3,4]. To better characterize the molecular properties of buforin IIIB and buforin IIIE, we investigated the effect of F-actin on the growth inhibition of $E$. coli by these peptides (Figure 3 ). F-actin was found to considerably decrease the growth inhibition of $E$. coli by both buforin III analogs. The inhibitory effect of actin on the antibacterial activity of the peptides decreased with increasing buforin concentration.

\subsection{Buforin III Analogs Bundle F-actin, and These F-actin Bundles can Be Dissociated by $\mathrm{NaCl}$}

Polyvalent cations bundle actin filaments [18] because the positively charged cations eliminate the repulsion between the negatively charged actin filaments [19]. As histone H2A, the parent molecule of buforin, also bundles actin [8], and the formation of actin bundles can have pathological consequences [20], it was of interest to study the interaction between buforin III derivatives and actin. Buforin IIIB and IIIE are polyvalent cations each containing eight extra positive charges. Therefore, it is expected that these buforin derivatives can bundle actin filaments. We monitored the bundling of F-actin by buforin IIIB and buforin IIIE using low speed centrifugation. After low speed centrifugation, bundled actin filaments sediment while unbundled filaments remain in the supernatant, allowing the separation of bundled and unbundled filaments using this method. Both buforin analogs were found to bundle F-actin (Figure 4). The bundling ability of buforin IIIE was considerably higher than that of buforin IIIB. Buforin IIIE bundled actin at concentrations that are substoichiometric relative to actin, at $1 \mu \mathrm{M}$, buforin IIIE bundled $57.1 \%$ of $4 \mu \mathrm{M}$ F-actin, while the same concentration of buforin IIIB bundled only $7.6 \%$ of the F-actin present. The results indicate that the binding of buforin IIIE to actin filaments is tighter than that of buforin IIIB.

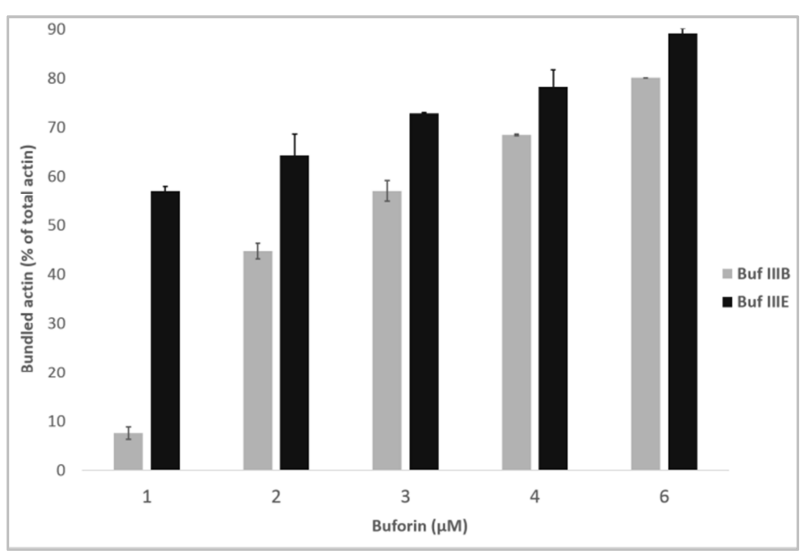

Figure 4. Bundling of F-actin by buforin IIIB and IIIE. Concentrations of 1$6 \mu M$ buforin IIIB and IIIE were added to $4 \mu M M g F$-actin in $p H 7.4 F$ buffer. Samples were centrifuged at 20,800 $\times \mathrm{g}$ for $8 \mathrm{~min}$, and supernatants were run on SDS-PAGE and evaluated as described in the Materials and Methods. The data presented represent the mean and standard deviation of three independent experiments. 
F-actin bundled by polycations is sensitive to ionic strengths and can be dissociated (unbundled) by high monovalent cation concentrations [18] because monovalent cations mask the electrostatic interactions between the polycations and the negatively charged actin filaments [19, 21]. The sensitivity of polycation-induced F-actin bundles to salt depends on the relative strengths of the electrostatic and hydrophobic interactions in the binding of the polycations to F-actin. Lower ionic strength sensitivity indicates an increased role of hydrophobic interactions in the binding of polycations to actin. We studied the effect of increasing $\mathrm{NaCl}$ concentration on the actin filaments bundled by buforin IIIB and buforin IIIE (Figure 5) and found that at up $100 \mathrm{mM}$ $\mathrm{NaCl}$ (physiological salt concentration), neither buforin IIIBbundled nor buforin IIIE-bundled actin filaments are dissociated. However, further increasing the $\mathrm{NaCl}$ concentration to $200 \mathrm{mM}$ almost completely dissociated buforin IIIB-bundled F-actin, while there was only a minor effect on buforin IIIE-bundled F-actin. In fact, buforin IIIEbundled F-actin was only insignificantly unbundled even in the presence of $300 \mathrm{mM} \mathrm{NaCl}$. The relatively low $\mathrm{NaCl}$ sensitivity of F-actin bundling indicated that there is a considerable role of hydrophobic interactions in the binding of both buforin III analogs to F-actin. The results also showed that these interactions are stronger with buforin IIIE than with buforin IIIB. Altogether, both the bundling and the salt dissociation experiments indicate that buforin IIIE binds more strongly to actin than buforin IIIB.

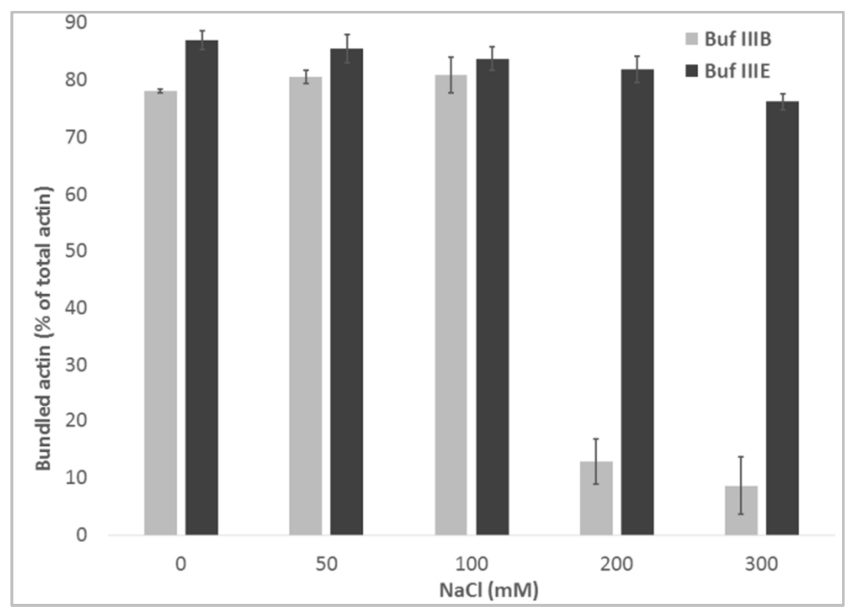

Figure 5. Effect of $\mathrm{NaCl}$ on the bundling of F-actin by buforins. Concentrations of 0-300 $\mathrm{mM} \mathrm{NaCl}$ were added to $4 \mu \mathrm{M} \mathrm{MgF}$-actin bundled by $6 \mu M$ buforin IIIB or buforin IIIE at $\mathrm{pH}$ 7.4. Samples were centrifuged at 20,800 $x \mathrm{~g}$ for $8 \mathrm{~min}$, and supernatants were run on SDS-PAGE and evaluated as described in the Materials and Methods. The data presented represent the mean and standard deviation of three independent experiments.

\subsection{Dissociation of Buforin III-Induced Actin Bundles by DNA and Binding of Buforin IIIB and IIIE to DNA}

Polyanions dissociate polycation-induced actin filament bundles as polyanions compete with negatively charged Factin for polycations. DNA, which is a highly negatively charged polyanion, was shown to unbundle histone-induced actin bundles [8]. We studied the effect of DNA on buforin
III analog-induced F-actin bundles with low speed centrifugation (Figure 6), as the buforin-DNA complex, unlike the F-actin-buforin complex, is not sedimented under this condition. There was no significant difference in the unbundling effect of DNA on the F-actin bundled by either buforin analog, as both the buforin IIIB-induced actin bundles and the buforin IIIE-induced actin bundles were nearly completely dissociated by $100 \mu \mathrm{g} / \mathrm{ml}$ DNA. The successful competition between DNA and actin for buforin binding indicates that DNA tightly binds both buforin analogs.

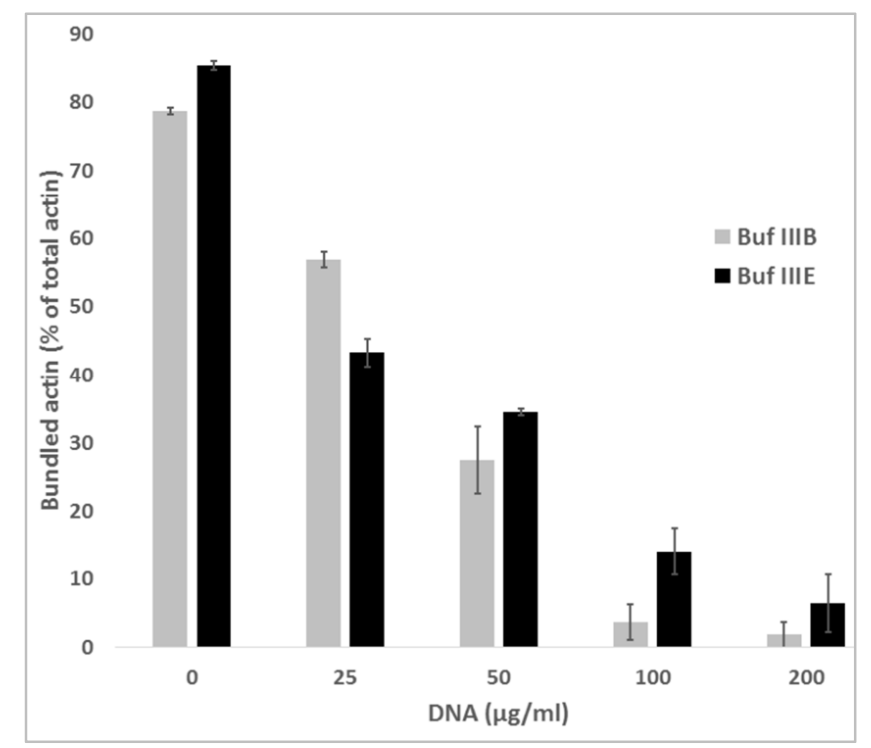

Figure 6. Effect of $0-200 \mu \mathrm{g} / \mathrm{ml} D N A$ on the dissociation of $4 \mu M$ F-actin bundled by $6 \mu \mathrm{M}$ buforin IIIB and buforin IIIE. Samples were centrifuged at 20,800 x g for $8 \mathrm{~min}$, and supernatants were run on SDS-PAGE and evaluated as described in the Materials and Methods. The data presented represent the mean and standard deviation of three independent experiments.

The binding of buforins to DNA was measured directly by a thiazole orange DNA binding assay [17]. This assay is based on fluorescent intercalator displacement, as DNAbound thiazole orange is highly fluorescent and its displacement from DNA by other ligands causes a sharp decrease in fluorescence [17]. Previous studies using this assay showed that the binding of buforin to DNA sequences is not selective [22], therefore, different DNA sources could be used for the measurement. We found that the addition both buforin analogs decreased the fluorescence of thiazole orange bound to DNA (Figure 7), indicating that thiazole orange is displaced by buforins. The displacement by buforin IIIE was significantly greater than the buforin IIIB-induced displacement, as the amount of buforin IIIE needed to decrease the thiazole orange fluorescence by $50 \%$ was much smaller than the amount of buforin IIIB. This result indicates that buforin IIIE more strongly binds to DNA than buforin IIIB. The finding that DNA and actin equally compete for the binding of the two buforin III analogs (Figure 6) while buforin IIIE binds more strongly to DNA than does buforin IIIB in the intercalator displacement assay seems to be controversial. However, the reason for this controversy is that 
while buforin IIIE binds more strongly to both actin and DNA than buforin IIIB, the relative actin and DNA binding strengths of the two analogs are about the same. Therefore, the competition between actin and DNA for buforin IIIE and buforin IIIB is similar.

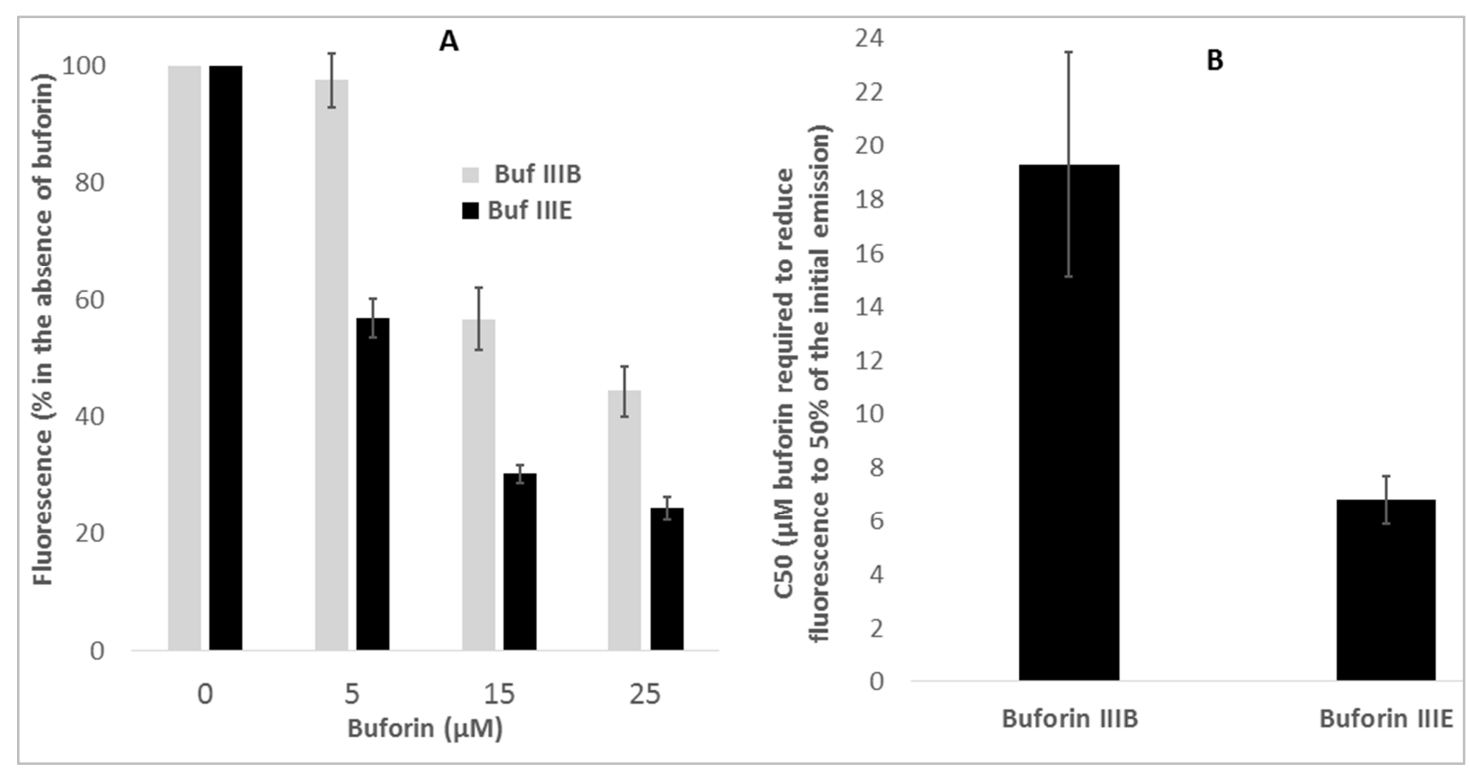

Figure 7. Buforin binding to DNA measured by the thiazole orange fluorescent intercalator displacement assay. (A) Concentrations of 0-25 $\mu M$ buforin IIIB or IIIE were added to $0.55 \mu \mathrm{M}$ thiazole orange in STE buffer containing $5 \mu \mathrm{g} / \mathrm{ml}$ DNA. Fluorescence was measured as described in the Materials and Methods (Thiazole orange DNA binding assay). Vertical axis: fluorescence (\% in the absence of buforin). (B) Concentration of buforin IIIB or IIIE needed to reduce the amount of thiazole orange bound to DNA by 50\%. The data presented represent the mean and standard deviation of three independent experiments.

\section{Discussion}

Buforin and its derivatives are efficient antimicrobial peptides that kill bacteria through translocation into the microbial cell without membrane disruption [13]. Their entrance into normal mammalian cells is greatly restricted, therefore, they have a high therapeutic index [23]. The selective entrance of buforin derivatives into microbial, but not mammalian, cells can be explained by the difference in the charge of their respective membranes. Microbial membranes are rich in negatively charged components, such as lipopolysaccharides, which have been suggested to constitute the chemoreceptors of positively charged peptides [24], whereas the outer layer of the mammalian cell membrane consists mainly of neutral phospholipids. Consequently, the binding affinity of cationic peptides to the membrane of mammalian cells is quite weak [25]. In addition to their antimicrobial activity, buforin II and its derivatives have also been shown to selectively kill cancer cells [26]. The selective anticancer activity of buforin IIB is also based on the charge difference between normal and cancerous mammalian cell membranes. Positively charged buforin IIB efficiently targets cancer cells whose outer plasma membrane surfaces contain high concentrations of negatively charged gangliosides [27], in contrast to the neutral outer surface of normal mammalian cell membranes. Buforin IIB can then traverse cancer cell membranes without disruption and induce either mitochondrial or endoplasmic reticulum stressdependent apoptosis [28].

We found that positively charged buforin IIIB and IIIE bind strongly to negatively charged DNA and F-actin polyanions. The strong DNA binding ability of these buforin III analogs should contribute to their high antimicrobial activity. Extracellular actin that has escaped from necrotic cells during inflammation could strongly bind to these analogs, which may cause a decrease in their antimicrobial activity, especially buforin IIIE, which binds actin very tightly. The bundling of extracellular actin by positively charged polycationic peptides or proteins can contribute to the pathology of cystic fibrosis by increasing the viscosity of sputum [20, 29, 30, 31]. Therefore, the tight binding of actin to buforin IIIE affects the possible therapeutic use of this analog.

We studied the role of hydrophobic residues in the antimicrobial activity and molecular characteristics of buforin IIIB by substituting all the valine residues with leucine residues in both the $\mathrm{N}$-terminal and $\mathrm{C}$-terminal helices to create the newly designed buforin III analog, buforin IIIE. As a consequence of the valine-leucine substitution, the antimicrobial activity of buforin IIIE decreased, and its binding to DNA and actin became stronger than that of buforin IIIB. The microbial cell killing mechanism of buforin III analogs is based on their translocation into the bacterial cell and their interaction with DNA inside the cell $[10,11]$. The role of buforin-DNA binding in the antimicrobial activity of this molecule has been supported by previous studies, which demonstrated that the positively charged buforin analogs strongly bound to the DNA polyanion [11, 22, 32]. Our results showing that the valine-leucine substitution increased DNA binding but decreased antibacterial activity is rather unexpected because if the antibacterial activity is dependent only on the strength 
of the peptide-DNA interaction, it would be expected that tighter DNA binding would be correlated with higher antibacterial activity. These unexpected results indicate that the antimicrobial activity of buforin III analogs depends on various other factors in the bacterial cell, in addition to the binding of DNA. Jang et al. [13] found that leucine-valine substitutions (buforin IIIC and buforin IIID) increased both the strength of the peptide-DNA binding and the antimicrobial activity. However, in their case, the positively charged amino acids in the $\alpha$-helices of the peptides were lysine, while in our experiments, these amino acids were arginine. The arginine-lysine substitution has also been shown to affect the antimicrobial activity of buforin derivatives [33], with the arginine derivatives having higher activities than the lysine derivatives. It seems that in the $\alpha$ helices, neither the hydrophobic nor the cationic amino acids alone determine the antimicrobial activity and DNA binding strength of the buforin III analog, instead, the two types of amino acid residues together have a decisive influence on these activities.

\section{Conclusions}

Our study supports the possible therapeutic role of buforin III analogs as efficient antimicrobial peptides that kill bacteria through translocation into the microbial cell without membrane disruption. Positively charged buforin IIIB and IIIE bind strongly to negatively charged DNA polyanions, which can contribute to their high antimicrobial activity. Buforin IIIB has higher antimicrobial activity than buforin IIIE because extracellular actin that escapes from necrotic cells during inflammation binds strongly to buforin IIIE, which may cause a decrease in the antimicrobial activity of this analog. The goal of future studies to determine how substitutions of amino acid residues in the sequence of buforin III analogs along with other factors affect the mechanism of antimicrobial activity.

\section{Acknowledgements}

This research was supported by the Hebrew University Science Fund (AM). The authors gratefully acknowledge the excellent technical assistance of Judith Goldstein.

\section{References}

[1] Jenssen H, Hamill P, Hancock R. Peptide antimicrobial agents. Clin Microbial Rev.2006,19: 491-511.

[2] Park CB, Kim MS, Kim SC. A novel antimicrobial peptide from Bufo bufo Gargarizans. Biochem Biophys Res Commun. 1996,218: 408-13.

[3] Kim HS, Yoon H, Minn I, Park CB, Lee WT, Zasloff M, Kim SC. Pepsin-mediated processing of the cytoplasmic histone $\mathrm{H} 2 \mathrm{~A}$ to strong antimicrobial peptide buforin I. J. Immunol. 2000,165: 3268-74.

[4] Kim HS, Park CB, Kim MS, Kim SC. cDNA cloning and characterization of buforin I, an antimicrobial peptide: a cleavage product of histone H2A, Biochem. Biophys. Res. Commun. 1996,229: 381-7.

[5] Hirsch JG. Bactericidal action of histone. J. Exp. Med. 1958,108: 925-44.

[6] Miller TE, Watson DW, Biochemical characterization of the antimicrobial histone released by deoxyribonuclease and lactic acid. Proc Soc Exp Biol Med. 1969,131: 339-42.

[7] Sol A, Skvirsky Y, Blotnick E, Bachrach G, Muhlrad A. Actin and DNA protect histones from degradation by bacterial proteases but inhibit their antimicrobial activity. Frontiers of Microbiology. 2016, 7: 1248 doi: 10.3389.

[8] Blotnick E, Sol A, Muhlrad A. Histones bundle F-actin filaments and affect actin structure. PLOS ONE. 2017,12: e0183760. https://doi.org/10.1371/journal.pone.0183760.

[9] Park CB, Yi K-S, Matsuzaki K, Kim MS, Kim SC. Structureactivity analysis of buforin II, a histone H2A-derived antimicrobial peptide: The proline hinge is responsible for the cell-penetrating ability of buforin II. Proc Natl Acad Sci U S A. 2000, 97: 8245-50.

[10] Park CB, Kim HS, Kim SC. Mechanism of action of the antimicrobial peptide buforin II: buforin II kills microorganisms by penetrating the cell membrane and inhibiting cellular functions. Biochem Biophys Res Commun. 1998,244: 253-7.

[11] Uyterhoeven ET, Butler CH, Ko D, Elmore DE. Investigating the nucleic acid interactions and antimicrobial mechanism of buforin II. FEBS Lett. 2008,582: 1715-18.

[12] Xie Y, Fleming E, Chen JL, Elmore DE. Effect of proline position on the antimicrobial mechanism of buforin II. Peptides. 2011,32: 677-82.

[13] Jang SA, Kim H, Lee JY, Shin JR, Kim DJ, Cho JH, Kim SC. Mechanism of action and specificity of antimicrobial peptides designed based on buforin IIb. Peptides. 2012,34: 283-9. doi: 10.1016 .

[14] Shafer WM Steinberg D, Lehrer RI. in Methods in Molecular Biology 78: Antibacterial Peptide Protocols, ed Shafer W M (Humana Press, Totowa, NJ), 1997, pp 169-186.

[15] Scudiero DA, Shoemaker RH, Paull KD, Monks A, Tierney S, Nofziger TH et al. Evaluation of a soluble tetrazolium/formazan assay for cell growth and drug sensitivity in culture using human and other tumor cell lines. Cancer Res. 1988, 48: 4827-33.

[16] Spudich JA, Watt S. The regulation of rabbit skeletal muscle contraction. I. Biochemical studies of the interaction of the tropomyosin-troponin complex with actin and the proteolytic fragments of myosin. J Biol Chem. 1971,246: 4866-71.

[17] Tse WC, Boger DL. A fluorescent intercalator displacement assay for establishing DNA binding selectivity and affinity. Acc. Chem. Res. 2004,37: 61-9.

[18] Muhlrad A, Grintsevich EE, Reisler E. Polycation induced actin bundles. Biophys Chem. 2011, 155: 45-51.

[19] Tang JX, Ito T, Tao T, Traub P, Janmey PA. Opposite effects of electrostatics and steric exclusion on bundle formation by F-actin and other filamentous polyelectrolytes. Biochemistry. 1997, 36: 12600-7. 
[20] Vasconcellos CA, Allen PG, Wahl ME, Draven JM, Janmey PA, Stossel TP. Reduction in viscosity of cystic fibrosis sputum in vitro by gelsolin. Science. 1994, 263: 969-7121.

[21] Tang JX, Janmey PA. The polyelectrolyte nature of F-actin and the mechanism of actin bundle formation. J Biol Chem. 1996,271: 8556-63.

[22] Sim S, Wang P, Beyer BN, Cutrona KJ, Radhakrishnan ML, Elmore DE. Investigating the nucleic acid interactions of histone-derived antimicrobial peptides. FEBS Letters. 2017, 591: 706-17.

[23] Zhu WL, Hahm KS, Shin SY. Cell selectivity and mechanism of action of short antimicrobial peptides designed from the cell-penetrating peptide Pep-1. J Pept Sci. 2009, 15: 569-75.

[24] Hirakura Y, Kobayashi S, Matsuzaki K. Specific interactions of the antimicrobial peptide cyclic b-sheet tachyplesin I with lipopolysaccharides. Biochim Biophys Acta. 2002,1562: 32-6.

[25] Hao G, Shi Y-H, Ya-Li Tang Y-L, Le G-W. The membrane action mechanism of analogs of the antimicrobial peptide Buforin 2. Peptides. 2009, 30: 1421-7.

[26] Lee HS, Park CB, Kim JM, Jang SA, Park IY, Kim MS, et al. Mechanism of anticancer activity of buforin IIb, a histone H2A-derived peptide. Cancer Lett 2008,271: 47-55.

[27] Bitton RJ, Guthmann MD, Gabri MR, Carnero AJ, Alonso 46
DF, Fainboim L, et al. Cancer vaccines: an update with special focus on ganglioside antigens. Oncol Rep. 2002,9: 267-76

[28] Jang JH, Kim YJ, Kim H, Kim SC, Cho JH. Buforin IIb induces endoplasmic reticulum stress-mediated apoptosis in HeLa cells. Peptides. 2015,69: 144-9.

[29] Brogan TD, Ryley HC, Neale L, Yassa J. Soluble proteins of bronchopulmonary secretions from patients with cystic fibrosis, asthma, and bronchitis. Thorax. 1975, 30:72-79. PMID: 4765636.

[30] Jay X. Tang JX, Wen Q, Bennett A, Kim B, Sheils CA et al. Anionic poly(amino acid)s dissolve $\mathrm{F}$-actin and DNA bundles, enhance DNase activity, and reduce the viscosity of cystic fibrosis sputum. Am J Physiol-Lung Cellular and Molecular Physiol. 2005, 289: L599-L605.

[31] Bucki R, Byfield FJ, Janmey PA. Release of the antimicrobial peptide LL-37 from DNA/F-actin bundles in cystic fibrosis sputum. Eur Respir J. 2007, 29: 624-32.

[32] Pavia KE, Spinella SA and Elmore DE. Novel histone-derived antimicrobial peptides use different antimicrobial mechanisms. Biochim Biophys Acta. 2012,1818: 869-76.

[33] Cutrona KJ, Kaufman BA, Figueroa DM, Elmore DE. Role of arginine and lysine in the antimicrobial mechanism of histone derived antimicrobial peptides. FEBS Lett. 2015,589: 391520 . 